\title{
Focus
}

\section{Een blijvend lastig thema: geweld}

\author{
H.G.L. Peels
}

Jacques van Ruiten and Koert van Bekkum (red.), Violence in the Hebrew

Bible between Text and Reception [Oudtestamentische Studiën 79]

(Leiden/Boston: Brill, 2020), x + 438 p., € 138,00 (ISBN 9789004434677).

\section{Ter inleiding}

Lange tijd is zowel in de kerkelijke praktijken als in de academische theologie het thema van geweld in de Bijbel onderbelicht gebleven. Typerend is dat een groot oudtestamenticus als Gerhard von Rad, die zelf twee wereldoorlogen had meegemaakt, in zijn veelgebruikte studie Der Heilige Krieg im alten Israel (1951) nergens de hermeneutische vraag naar het problematische gebruik van geweld in het Oude Testament aan de orde stelt. Ook in oudtestamentische theologieën werden geweldsteksten vaak genegeerd en gepasseerd, als waren ze 'the elephant in the room of which nobody speaks'. Dit is met name sinds de geweldsexplosie van nine eleven snel veranderd. Een lange reeks monografieën en vele artikelen zijn de afgelopen twee decennia aan dit lastige thema gewijd. Acties van religieus gemotiveerde terreurgroepen als Al Qaeda en ISIS hebben voor de moderne westerse mens niet alleen de Koran maar indirect ook de Bijbel in een verdacht licht gezet. Immers, 'commands to kill, to commit ethnic cleansing, to institutionalize segregation, to hate and fear other races and religions (...) all are in the Bible, occurring with a far greater frequency than in the Qur'an'.1

Het moeilijkst is voor kerkelijke en zeker voor onkerkelijke bijbellezers de lange rij 'God-en-geweldverba': God roeit uit, vernietigt, slaat neer, doodt, slacht af, doorboort, maakt kinderloos, verscheurt, maakt ziek, laat verhongeren, strijdt, verstrooit, verdrijft, voert in ballingschap, steekt in brand, vergeldt, vervloekt, veroordeelt, reikt de beker des toorns, et cetera. In onze secu-

1 Ph. Jenkins, Laying Down the Sword: Why We Can't Ignore the Bible's Violent Verses (New York: HarperOne 2011), 71. 
liere context zijn deze bijbelteksten voor de lezer, die veelal een diepe afkeer heeft gekregen van alle geweld in de wereld rondom, een groot struikelblok. Niet voor het eerst in de geschiedenis, natuurlijk. Het gedachtengoed van Marcion herleeft in onze dagen: waarom zou het Oude Testament nog langer Woord van God voor de kerk van nu moeten zijn (dogmaticus Notger Slenczka, Humboldt-Universität Berlijn)? De felle kritiek van Celsus (tweede eeuw) en Porphyrius (derde eeuw) op de Bijbel krijgt een krachtige update in de publicaties van new atheists als Richard Dawkins en Sam Harris, en de door een breed publiek gelezen boeken van de literatoren Guus Kuijer en Dmitri Verhulst.

De theologisch-wetenschappelijke doordenking van het geweldsthema in de Bijbel bevindt zich echter nog maar in een beginfase. Daarom was het een goede greep van het bestuur van Het Oudtestamentisch Werkgezelschap in Nederland en België om dit thema als onderwerp voor een internationale conferentie te kiezen, en de zusterorganisaties The Society for Old Testament Study (Verenigd Koninkrijk en Ierland) en Die Ou Testamentiese Werkgemeenskap in Suid-Afrika (Zuid-Afrika) hiervoor uit te nodigen. Het was de eerste trioconferentie ('Joint Meeting') van deze organisaties, gehouden in Groningen augustus 2018. De meeste daar gehouden lezingen zijn nu gebundeld in Violence in the Hebrew Bible between Text and Reception, als deel 79 in de door de drie organisaties geredigeerde Brill-reeks Oudtestamentische Studiën. De redacteurs van dit deel, de RUG-hoogleraar Jacques van Ruiten en de ETF/TUK-hoogleraar Koert van Bekkum, zullen er veel werk aan hebben gehad, maar het resultaat mag er dan ook zijn. Een boeiend boek, niet alleen vanwege de verbreding van de thematiek naar de receptiegeschiedenis, maar zeker ook door de ontmoeting van perspectieven uit geheel verschillende culturen.

\section{Tekst en receptie}

Deze bundel bevat na de introductie negentien bijdragen, die een breed palet van invalshoeken weerspiegelen. Sommige richten zich primair op de bijbeltekst in de eigen literaire en socio-historische context, andere brengen daarnaast aspecten van de vroege en latere receptiegeschiedenis in beeld, weer andere bieden een bespreking vanuit een existentiële reader-responsbenadering. In de overlevering van de bijbelteksten openen zich allerlei theologische en ideologische perspectieven. Wirkungsgeschichte en receptiegeschiedenis roepen tegelijk weer de vraag op naar een kritische toetsing aan de bijbeltekst zelf. Geen bijbellezer kan 'objectiviteit' en het alleenrecht van een juist verstaan claimen, het is steeds weer een zoektocht hoe we recht moeten doen aan de strekking van bijbelteksten in hun eigen literair-historische en culturele 
contexten, en hoe we de dialoog met latere ontvangers in hun contexten hebben te realiseren. De interactie met de brontekst zelf en zijn claims is hierbij van blijvend belang.

Het boek bestaat uit vijf delen. Het eerste deel heeft met drie bijdragen een min of meer inleidend karakter (Violence in the Hebrew Bible). Daarna volgen vier delen naar de structuur van de Hebreeuwse canon: Violence in the Torah (vier artikelen), Violence in the Former Prophets (zes artikelen), Violence in the Latter Prophets (drie artikels) en Violence in the Writings (drie artikelen). Uit elk van de delen bespreek ik een of twee bijdragen, om in dwarsdoorsnee een impressie van dit indringende boek te geven.

In het inleidend deel zet Jacques van Ruiten de coördinaten van de thematiek uit: waar praten we over, als we het hebben over religieus gemotiveerd geweld. Zowel 'religie' als 'geweld' is een lastig te definiëren term. Bovendien is het Oude Testament, waarin zoveel geweld voorkomt, tegelijk het boek van troost en hoop, een bron van inspiratie voor sociale gerechtigheid. Een boek dat oproept tot vrede, en aanmoedigt geweld te beëindigen - maar nochtans veel problematische passages bevat. In de loop der tijden zijn verschillende hermeneutische strategieën toegepast in de omgang met de geweldsteksten. Vanouds zoals bekend de allegorisch-harmoniserende aanpak, die de teksten eenvoudigweg neutraliseert. Daarnaast de oudere godsdiensthistorische benadering, met de idee van een evolutie van de stamgod tot een universele wereldheerser (Wellhausen), waarbij in een latere fase het godsbegrip van eerdere fasen wordt gecorrigeerd en gefilterd, en het geweld al meer uitgebannen. Vergelijking met Umwelt-literatuur vindt ook veel plaats: Israël was een kind van zijn tijd, en de notie van goddelijk geweld was toen alom gangbaar. Weer anderen gaan selectief met de teksten om, de voorkeur gevend aan ethisch acceptabele teksten boven geweldsteksten. Voor een gereformeerd exegeet meer herkenbaar is de canonieke benadering, die poogt de geweldsteksten te lezen in het kader van een totaalverhaal, de brede context van de héle Bijbel. Bij een reader-responsbenadering treedt de exegeet in kritische interactie met de tekst, met name wanneer deze uitspraken bevat die moreel onacceptabel lijken te zijn. Ten slotte is de inbreng van de historisch-kritische wetenschap van belang, die de afstand tussen tekst en geschiedenis accentueert: gaat het om daadwerkelijke geschiedenis, of om ideologische constructies uit later tijd die eigen claims promoten? Gaat het om literaire teksten van een genre dat een meer figuurlijke uitleg vergt, gelet op het gebruik van metafoor en hyperbool in vergelijkbare oudoosterse literatuur? Het veld van hermeneutische posities dat Van Ruiten schetst is niet compleet, maar maakt wel duidelijk hoe gecompliceerd de vragen zijn en hoe gevarieerd de invalshoeken. Diverse ervan vind je in de bundel zelf ook terug. 
Technisch maar inzichtgevend is de bijdrage van de emeritus hoogleraar David Clines uit Sheffield, bekend van de prachtige en veelgebruikte Dictionary of Classical Hebrew. Hij doet een poging om een semantisch veld van fysiek geweld in het bijbels Hebreeuws te schetsen, en komt dan tot de conclusie dat ongeveer vijfhonderd termen hiervoor gebruikt worden in het Oude Testament. Van de 10.033 keer dat een geweldsterm voorkomt, zijn er 1.865 van toepassing op God (dat is 18,6\%). Enigszins merkwaardig is het slot van het artikel, waarin Clines de vraag stelt of deze aantallen meevallen of niet - omdat van de 303.500 woorden die het Oude Testament telt dus eigenlijk maar 3,3\% (die 10.033 keer dat een geweldsterm wordt gebruikt ) over geweld gaat. Is dit een groot percentage? De lezer mag de vraag beantwoorden, aldus Clines. Misschien iets van Engelse humor?

\section{Geweld in de Tora}

In een fascinerend artikel richt Koert van Bekkum zich op de interpretatie van een van de meest gewelddadige gedeelten in het Oude Testament: Genesis 6-8. Het zondvloedverhaal heeft een lange receptiegeschiedenis gekregen, tot op heden toe (denk aan de ecologische crises met stijgend niveau van de oceanen!). De onderzoeksfocus op het motief van goddelijk geweld brengt basale overtuigingen aan het licht die in en achter de teksten liggen, ten aanzien van de aard van het geweld, en van de verhouding tussen God/goden en mensen. In de oud-Mesopotamische mythen van Gilgameš en Atrachasis zijn goddelijk geweld en wispelturigheid een gegeven, zowel goden als mensen moeten hun plaats in de geschapen werkelijkheid leren innemen via het trauma van de vloed. Het verhaal draagt bij aan menselijk bewustzijn: de goden zijn uiteindelijk afhankelijk van de mens. Met een knappe analyse van Genesis 6-8 in de context van Genesis 1-11 laat Van Bekkum zien hoe - bij alle gelijkenis tussen Genesis en de oud-Mesopotamische teksten - er duidelijke verschillen zijn: de volle verantwoordelijkheid voor de ramp ligt bij de mens, wiens geweld de goede schepping bedorven heeft. Gods geweld is vergelding daarvoor, die tegelijk de mogelijkheid van een nieuw begin brengt - hoe moeilijk ook, vanwege de blijvend zondige aard van de mens. God is niet afhankelijk van de mens, maar Hij wil met hem verder. De receptie van het zondvloedverhaal in 1 Henoch en Jubileeën gaat eigen wegen: de gevallen engelen zijn verantwoordelijk voor de verspreding van het kwaad op aarde, de relatie tussen de schepping en de Allerhoogste is meer indirect. Ten slotte bespreekt Van Bekkum de film Noah van Darren Aronofsky (2014), waarin God nog meer op afstand komt te staan en de mens geheel verantwoordelijk wordt gesteld voor kwaad en geweld in de wereld.

Een kerntekst in de discussie over geweld in het Oude Testament is 
Deuteronomium 7, over het gebod de Kanaänitische volken met de ban te slaan. Geen verbond, geen genade. Jacques van Ruiten laat in zijn bespreking van deze tekst diverse visies de revue passeren: het doel van het gebod was om Israël dicht bij JHWH te houden; het betreft de droom van een machteloze groep; geen letterlijke uitleg want het gaat over volken die niet meer bestaan. Van belang is hierbij ook de vergelijking met Exodus 23 en 34, en ook Ezra 9-10. Vervolgens traceert Van Ruiten de manier waarop in het boek Jubileeën (tweede eeuw voor Christus) de tekst van Deuteronomium 7 doorwerkt, met name in de afscheidsrede van Mozes, met een toespitsing op de reinheid van het volk Israël tegenover de onreinheid van de Kanaänieten. Het gebod om de Kanaänieten uit te delgen ontbreekt hier, en in plaats daarvan is sprake van een vloek die Kanaän over zichzelf heeft afgeroepen. In de latere christelijke receptie zie je enerzijds een spiritualisering van de tekst en anderzijds een bedenkelijk misbruik ervan in de rechtvaardiging van moorddadige acties richting andere volken.

\section{Geweld in de Vroege Profeten}

In mijn herinnering maakte tijdens de conferentie de bijdrage van June F. Dickie, postdoc aan de universiteit van Kwazulu-Natal, veel indruk. Zij vertelde hoe zij pastoraal werk verricht in een gevangenis voor vrouwen, die in detentie zijn na een veroordeling voor moord op of geweld tegen hun eigen man - doorgaans vanwege diens wangedrag. Vrouwen, die mishandeld worden en ten einde raad een mes uit de keukenla pakken... Met deze vrouwen heeft zij in bijbelstudie de tekst uit Richteren 4-5 behandeld, over Jaël die met een hamer een tentpin door de schedel van krijgsheer Sisera slaat. Hoe reageren deze vrouwen op dit bijbelverhaal? In de literatuur wordt Jaël op heel verschillende manieren geportretteerd: als een dappere heldin en als een bedrieglijke moordenares. Een analyse van de bijbelteksten laat zien dat haar actie in het kader staat van de dreiging van de vijand, bedoeld om Israël aan te zetten tot deelname aan de strijd die Godes is. Jaël zet de wapens in die zij heeft: seksualiteit en huisgerei. Maar is het goed, wat zij doet? Frappant is hoe gemengd de vrouwen in de gevangenis deze vraag oppakten. Aanvankelijk was de reactie negatief: moord is fout, maar er zijn verzachtende omstandigheden. Geweld is altijd verkeerd, maar onder bepaalde voorwaarden toch acceptabel. De seksuele connotaties van het verhaal, die bij moderne lezing vaak over het hoofd worden gezien, werden door deze vrouwen onmiddellijk opgepakt. Onmiskenbaar geeft het perspectief van zwarte vrouwen, zelf lijdend onder geweld en pijn, de tekst over Jaëls moord een nieuwe dimensie.

Even boeiend is de bijdrage van Paul Sanders, universitair docent Oude 
Testament aan de PThU Amsterdam. Hij behandelt de gruweltekst over de executie van de zeven Sauliden in 2 Samuël 21, door David uitgeleverd aan de Gibeonieten, die hen in Gibea ophangen 'voor het aangezicht van JHWH'. Hun dode lichamen worden bewaakt door Rizpa, die het gedierte verjaagt. $\mathrm{Na}$ de gepaste begrafenis van het gebeente van Saul en Jonathan, samen met dat van hun zonen, komt er een einde aan Gods toorn over het land. Een geschiedenis die veel vragen oproept - wat was de rol van David hierin? Vanuit een hermeneutiek van suspicion komt hij er niet zo goed van af: David had veel voordeel bij deze actie. Het hoofdpunt van Sanders' bijdrage ligt in de vergelijking van 2 Samuël 21 met drie buitenbijbelse teksten (twee 'pestgebeden' van de Hethitische koning Mursili II en de neo-Assyrische tekst 'de zonde van Sargon II'). Deze teksten vertonen veel gelijkenis met het gebeuren in 2 Samuël 21, over hoe een koning verantwoordelijk moet handelen in een bedreigende situatie van ziekte, honger of ellende. In het licht van deze conceptuele parallellen is het mogelijk om kritische reacties op het verhaal van 2 Samuël 21 beter te evalueren. Tegelijk, hoe 'vreemd' deze tekst ook voor ons is, krijgen we hierdoor meer oog voor positieve aspecten: omdat God over de gezworen eed waakt, zet dit de vorst aan tot het respecteren van een verdrag. Dit impliceert tevens een meer zelfkritische houding, en begrip voor zwakkere groepen in de samenleving die gemakkelijk worden overruled. Hoe afstotend ook, bemoedigt 2 Samuël 21 de lezer om te strijden voor gerechtigheid en vreedzame vormen in de omgang van mensen met elkaar.

\section{Geweld in de Late Profeten en in de Geschriften}

Wim de Bruin, PKN-predikant te Bleiswijk, onderzoekt in zijn bijdrage hoe in de masoretische volgorde van het dodekapropheton het boek Micha in zekere zin bemiddelend kan zijn tussen het boek Jona enerzijds en het boek Nahum anderzijds. Nahum staat vol met de taal van Gods wraak en geweld, gericht op Nineve, terwijl Jona de boodschap van Gods berouw en geduld bevat, bestemd voor hetzelfde Nineve. Targum Jonathan heeft de spanning tussen Jona en Nahum al gevoeld, blijkens een toevoeging bij Nahum 1:1, dat ondanks de eerdere bekering na de prediking van Jona, Nineve later toch weer in zonde was gevallen, om welke reden nu Nahum moest optreden. In het bijbelwetenschappelijk onderzoek worden de boeken Jona en Nahum niet zelden als contradictoir geïnterpreteerd, of wordt gesteld dat Jona een latere correctie op de harde boodschap van Nahum is. De Bruin biedt in zijn intertextueel onderzoek met name een analyse van het perspectief op de vijand in de drie genoemde boeken. Zowel in Jona als in Micha speelt de echo van Israëls credo uit Exodus 34 een rol, maar in geheel verschillende toepassing. Hiertussenin ligt het boek Micha, dat een complexe ontstaansgeschiedenis 
heeft, hetgeen zich ook weerspiegelt in verschillende perspectieven op de vijand (De Bruin onderscheidt er maar liefst twaalf). Ook aan het slot van Micha wordt gezinspeeld op het credo van Exodus 34. Micha 7:18-20 is een 'mediating voice' tussen de centrale boodschap van Jona enerzijds, en ook - vanwege de notie van Gods eed aan de vaderen en het behoud van de rest van Gods erfdeel (wat de verlossing uit de macht van de vijand impliceert) - van de prediking van het boek Nahum. Van een specifieke Fortschreibung in Micha, om dit boek de thematiek van de naties in Jona en Nahum te laten systematiseren, is geen sprake. Wel van een multiperspectiviteit op de vijand in de finale versie van Micha, waardoor dit boek bij uitstek geschikt is om tussen Jona en Nahum te 'bemiddelen' en om het dispuut over de diepe vragen die hier liggen, gaande te houden.

Als laatste noem ik het artikel van Arie Versluis, CGK-predikant te Ede en geassocieerd onderzoeker aan de TUA. Onder de prikkelende titel 'Knock the Little Bastards' Brains Out' (ontleend aan C.S. Lewis) biedt zijn goedgedocumenteerde bijdrage een beknopte receptiegeschiedenis en theologische interpretatie van Psalm 137:9. Geen tekst in het Psalter stoot de moderne bijbellezer meer af dan deze, terwijl Psalm 137 in de tijd van de Reformatie nota bene een van de meest vertaalde en gebruikte psalmen van alle was (p. 373 noot 3). In onze dagen is de sensitiviteit ten aanzien van de ethische problematiek van dit soort teksten echter aanzienlijk groter dan in vroeger tijden. Allegorese en antithese, bekende interpretatieve mechanismen de eeuwen door, voldoen niet. In een zorgvuldige exegese van de tekst in zijn context toont Versluis aan dat vers 7 een integrerend onderdeel van het hele lied is. De historische context draagt stellig bij aan het verstaan ervan (cf. de relatie met Jesaja 13 en Jeremia 50), evenals het zicht op de finale intentionaliteit van het Psalter als 'Davids dagboek' (Zenger). Vijf belangrijke aspecten worden genoemd om de tekst beter te plaatsen: a) het thema van het contrast tussen Babel en Sion, b) het ius talionis als rechtsprincipe, c) de focus ligt áchter het gewelddadige beeld op het afbreken van een mogelijke toekomst voor Babel, d) de link met profetische voorzeggingen elders, e) het is een gebed tot God, en niet een middel om zichzelf recht te verschaffen.

Nadat alles is onderzocht en gezegd, eindigt Versluis met een eerlijke uitspraak, die ik hier in zijn geheel citeer: 'None of these points resolve my moral problems with the end of Psalm 137. If I read the text again, I would still prefer it not to be there, or at least not in this form. But it is there, and simply rejecting or ignoring it is no way out. Psalm 137 confronts us with the depths of human atrocities and revenge, with the question of whether we are apathetic to suffering and injustice, and with a cry out of the depths, a cry to God for his justice' (p. 393). 


\section{Breder verband}

De ruimte ontbreekt om nader in te gaan op andere belangwekkende bijdragen in deze bundel, zoals die van Christo Lombaard over Genesis 22 (de Aqedah), Miracle Ajah over Numeri 25 (de actie van Pinehas), Cor de Vos en Ntozakhe Cezula over het boek Jozua, Klaas Spronk over Richteren 21 (de bruiden voor Benjamin) of Tsaurayi K. Mapfeka over Esther 9 (de slachting in Susa). Niet alle artikelen zijn even overtuigend, wel zetten ze alle aan tot verder nadenken. En wie zal ontkennen dat dat hard nodig is. Voor de gemiddelde bijbellezer is het een onthutsende ervaring om te ontdekken dat het meest prominente antropologische thema in het Oude Testament dat van het geweld is. ${ }^{2}$ Voor de exegese en de bijbelse theologie van het Oude Testament ligt hier een bijzondere opgave, vandaag de dag meer dan ooit. Het geweldsthema staat hoog bovenaan op de politieke, sociale en religieuze agenda van de moderne samenleving.

Mede door de participatie van oudtestamentici uit de Afrikaanse context, die soms heel andere invalshoeken kiezen dan die van de westerse academische theologie, is de bundel Violence in the Hebrew Bible een waardevol boek geworden dat ons laat zien hoezeer in de analyse en evaluatie van geweldsteksten de eigen positie en context van de interpreet een rol speelt. Enerzijds is een 'objectieve' lezing van de tekst illusoir, anderzijds mag de tekst in zijn eigenheid kritisch inwerken op onze interpretatie.

In een conferentie van oudtestamentici is het niet te doen gebruikelijk om ook het Nieuwe Testament ter sprake te brengen. Maar hier ligt nog wel veel huiswerk: hoe de lijnen van Oud naar Nieuw door te trekken. In zekere zin behoort ook het Nieuwe Testament tot de Wirkungs- en receptiegeschiedenis van het Oude Testament. Juist als je het geweldsthema in breder bijbels-theologisch licht wilt bezien, wordt het spannend. Ook dan ontwikkelen zich verschillende hermeneutische posities. Een dialectische hermeneutiek, die wet en evangelie naast elkaar zet: de mortificatio door het Oude Testament met zijn geweldsteksten en de vivificatio door het Nieuwe Testament met de boodschap van verzoening. Of een eclectische hermeneutiek, die een toenemende lijn van šaloom in het Oude Testament ziet uitmonden in het Nieuwe Testament, terwijl de lijn van hamas (geweld) in het Oude Testament wordt afgesloten en afgewezen. Of een christocentrische uitleg: 'The biblical Christ is the criterion of the biblical God'. Oudtestamentische beelden van een

2 'Keine andere menschliche Tätigkeit oder Erfahrung wird so oft erwähnt (wie die Gewalttat), weder die Welt der Arbeit und Wirtschaft, noch die der Familie und Sexualität oder der Naturerfahrung und des Wissens' (R. Schwager, Brauchen wir einen Sündenbock? Gewalt und Erlösung in den biblischen Schriften (München: Kösel 1978), 58. 
gewelddadige God kunnen niet realiter zo bedoeld zijn, zo ís God niet. Er is onderscheid tussen de 'textual God' en de 'actual God' (E. Seibert). Verder komen we mijns inziens met een canonieke benadering, die de heilshistorische grondstructuur van de Bijbel en tevens het bijbelse Godsbeeld in zijn volle diepte zoekt te verdisconteren. ${ }^{3}$

Ieder beseft: geweld in de Bijbel is en blijft een lastig thema. Een brede, gezamenlijke bezinning ter zake is van veel belang. De OTS-bundel Violence in the Hebrew Bible levert hieraan een bijdrage, waar we de redactie dankbaar voor zijn. De prijs is stevig (tsja: Brill...), 'maar dan heb je ook wat'. We zien uit naar meer van dit soort vruchten van bijbelwetenschappelijk onderzoek.

3 Onbevredigend zijn snelle antwoorden zoals die gegeven worden in de 'just cause' benadering ('de Kanaänitische volken verdienden dit lot want zij waren extreem bedorven') of de 'greater good'- benadering ('uitroeiing van de Kanaänitische volken was noodzakelijk om Israël te behoeden voor afval'). Cf. ook mijn God en geweld in het Oude Testament (Apeldoornse Studie 47), Apeldoorn: Theologische Universiteit $2017^{2}$. 